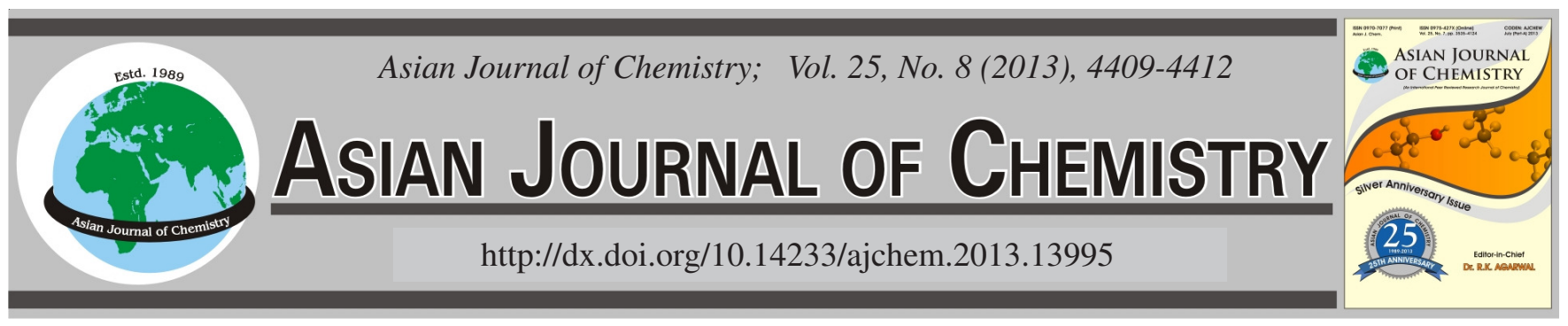

\title{
Organic Pollutant Levels in Sediments of Ennore, India
}

\author{
USHA NATESAN
}

Centre for Water Resources, Anna University, Chennai-600 025, India

Corresponding author: E-mail: u_natesan@yahoo.com

(Received: 30 April 2012;

Accepted: 11 February 2013)

AJC-12976

\begin{abstract}
The surface sediment samples are an easy sink for the pollutants especially organic pollutants. Dioxins and furans were analyzed in ten surface sediments from a highly contaminated water body, Ennore Creek, southeast coast of India. USEPA procedure was followed for processing and quantifying the levels of organic pollutants by HRGC/LRMS. Total organic carbon and sediment composition were analyzed to find their association with the organic pollutants. The most abundant organic pollutant is the phthalate esters of high molecular weight followed by polycyclic aromatic hydrocarbons the main source being refineries and other chemical industries situated in the vicinity of the study area.
\end{abstract}

Key Words: Dioxin, Ennore, Organic Pollutants, Sediment, USEPA.

\section{INTRODUCTION}

Marine pollution is a major concern of modern times as oceans have become a sink for various industrial effluents and domestic wastewater. Therefore there is a need to study in the physical and chemical behaviour, fate in the environment and potential to cause harm in the long run. The Stockholm convention on persistent organic pollutants is a global treaty aiming to protect human health and the environment from persistent organic pollutants. Persistent organic pollutants are linked to serious health effects in humans and other species including reproductive and developmental illness, immune suppression, nervous systems disorders and cancer and hormone disruption. Every living organism on earth now carries measurable levels of persistent organic pollutant chemicals in its tissues. Because of their particular characteristics, production or use of persistent organic pollutant chemicals anywhere threatens people and the environment everywhere. According to Hurst et al. ${ }^{1}$ dioxinlike compounds belong to a class of compounds called polyhalogenated aromatic hydrocarbons and include congeners of polychlorinated dibenzo- $p$-dioxins, dibenzo-furans (PCDFs) and biphenyls (PCBs). Dioxin-like compounds are ubiquitous in the environment ${ }^{2}$ and their presence is primarily the result of by-products of human activities including industrial ${ }^{3}$ and other sources (e.g. waste incineration $\left.{ }^{4}\right)$. Polycyclic aromatic hydrocarbons are among the most ubiquitous pollutants, with their concentration increasing due to the dependency of human communities to the fossil fuels ${ }^{5}$. The present study aims at understanding the dioxin and furan contamination levels and to elucidate their spatial distribution in coastal sediments of Ennore, a major industrial area in Tamil Nadu.

\section{EXPERIMENTAL}

Ennore creek, Chennai is surrounded by industrial complexes, and receives treated and untreated industrial effluent, urban sewage and coolant water from the thermal power stations. This region could possibly be contaminated by some unknown persistent organic compounds like dioxins and furans. Hence an attempt was made to detect the organic pollutant levels in the sediments from Ennore Creek and to find out their correlation with other sediment parameters.

Ennore Creek which is located at latitude $13^{\circ} 13^{\prime} 03^{\prime \prime} \mathrm{N}$ and longitude $80^{\circ} 19^{\prime} 18^{\prime \prime} \mathrm{E}$, is an estuary that drains the Koratalliyar River. It is located in the northeastern part of Chennai city along the coast of Bay of Bengal. It is $3 \mathrm{~km}$ long and $1 \mathrm{~km}$ wide. The depth of the creek ranges from $0.5 \mathrm{~m}$ to $3 \mathrm{~m}$. The Koratalliyar river flows sluggishly during summer and some excess outflow is observed during the monsoon season. Kosastaliyar river which is connected to the Pulicat Lagoon in the north also discharges its water. The Buckingham canal is another source of polluted water that flows into the creek. It is an estuarine ecosystem with regular flux of seawater and river water. Stunted mangroves are found in the creek arm. The minimum and maximum temperature ranges are 20-28 ${ }^{\circ} \mathrm{C}$ and $28-37^{\circ} \mathrm{C}$ respectively. The region receives most of its rainfall from the northeast monsoon during October and November. Tides at Ennore are semi diurnal having two spring and neap tides every day. The heavy land based activities in 
TABLE-1

ORGANIC CONTAMINANTS IN SEDIMENTS FROM ENNORE CREEK

\begin{tabular}{|c|c|c|c|c|c|c|c|c|c|c|c|}
\hline \multirow{2}{*}{ Organic pollutant detected } & \multirow{2}{*}{$\begin{array}{c}\text { m.w. } \\
(\mathrm{g})\end{array}$} & \multicolumn{10}{|c|}{ Concentration of organic pollutant in station $(\mathrm{mg} / \mathrm{g})$} \\
\hline & & 1 & 2 & 3 & 4 & 5 & 6 & 7 & 8 & 9 & 10 \\
\hline \multicolumn{12}{|l|}{ Phthalate esters } \\
\hline 1,2-Benzenedicarboxylic acid, diisooctyl ester & 390 & 2.907 & 0.112 & - & 0.570 & - & 5.202 & 0.002 & 0.0 & NIL & 0.050 \\
\hline Phthalic acid, nonyl 2-pentyl ester & 362 & - & - & 2.590 & - & - & - & - & - & NIL & - \\
\hline \multicolumn{12}{|l|}{ РАН } \\
\hline Naphthalene,1,6,7-trimethyl- & 170 & - & 0.077 & - & - & - & - & - & - & NIL & - \\
\hline Phenanthrene & 178.22 & - & - & 0.111 & - & - & - & - & - & NIL & - \\
\hline Anthracene,2-methyl- & 192 & - & - & - & - & - & 0.369 & - & - & NIL & 0.067 \\
\hline 1,1'-Biphenyl,3-methyl & 168 & - & - & - & 0.540 & - & - & - & - & NIL & - \\
\hline 1,1'-Biphenyl,3,4'-dimethyl- & 182 & - & 0.056 & - & - & - & - & - & - & NIL & - \\
\hline \multicolumn{12}{|l|}{ Other organic pollutants } \\
\hline Benzocycloheptatriene & & - & - & - & - & 1.507 & - & - & - & NIL & - \\
\hline Butanoic acid, 3-[(1-phenylethyl-2-propynyl)oxy] & 246 & - & - & - & - & 1.452 & - & - & - & NIL & - \\
\hline Methoxyacetic acid, 2-tetradecyl ester & 286 & - & - & - & - & - & 1.323 & - & - & NIL & - \\
\hline
\end{tabular}

the Manali industrial belt and the sewage from the North Chennai region leads to the effluent discharges into the upper reaches of the Ennore creek. Coal-powered North Chennai Thermal Power Station situated very close to the creek drains the coolant water near the creek mouth. This region is highly polluted with known and unknown industrial sources ${ }^{6}$.

Sample collection and analysis: The sampling stations extend along the creek region which is influenced by various forms of land based activities (Fig. 1). Station 1 is where the Ennore thermal power plant draws water from the creek for cooling purposes. Stations 2, 3 and 4 lie in the stretch that is intercepted by mangroves and biological activities. There is a railway bridge across the creek, where the wastewater and effluents flowing in the Buckingham canal mix in the creek which was chosen as station 5. Stations 6 and 7 are influenced by the intrusion of seawater and the subsequent mixing of it with the river water. Station 8 and 9 receive the coolant water from the North Chennai thermal power plant and boating activities respectively. Station 10 is located near the mouth of

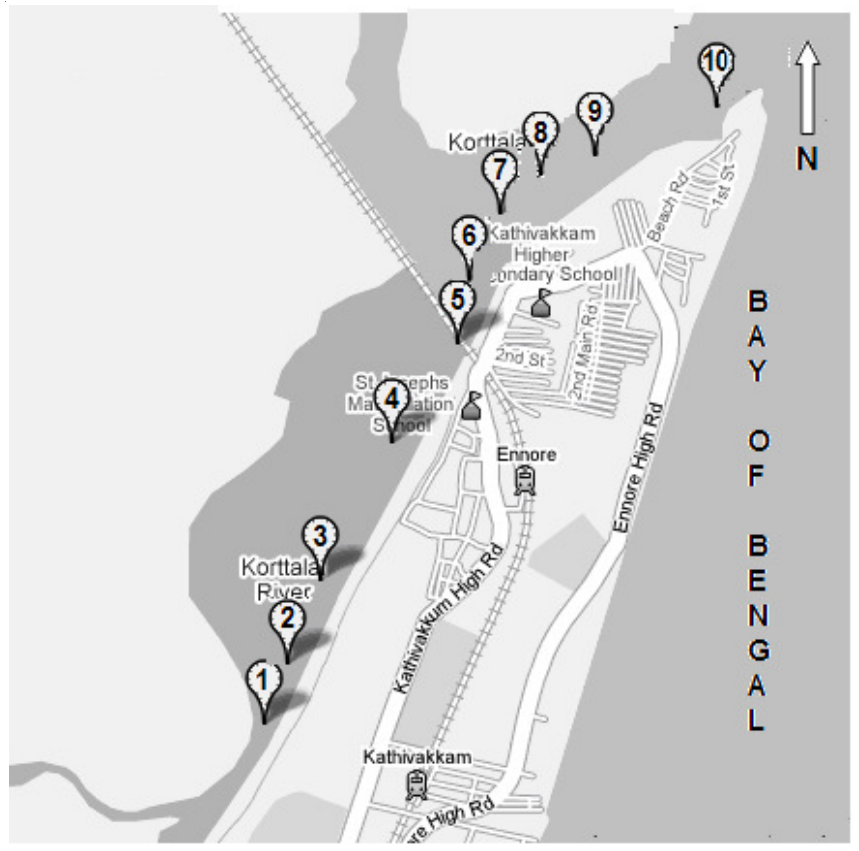

Fig. 1. Sampling stations around Ennore creek the creek. In spite of continuous dredging, the sand bar formation is of a major concern in this station. Domestic activities are carried out along the banks of the sampling stretch from stations 1 to 6 , whereas station 7 to 10 shows lot of shell fish collection and fishing activities. The exact location of sampling stations was determined with the help of the geographic positioning system. Sediment was collected using a grab sampler from motor boats at each station and stored in labeled polyethylene bags.

The samples were air dried for three to four days and large debris was manually removed. The samples were analyzed using gas chromatography coupled with mass spectrometry following USEPA method $8280 \mathrm{~A}^{7}$. Total organic carbon ${ }^{8}$ and sediment composition ${ }^{9}$ were also determined. The correlation of the levels of organic pollutants and other parameters of the sediments were found by the Spearman's rank correlation coefficient ${ }^{10}$ between the parameters.

\section{RESULTS AND DISCUSSION}

From the HRGC/LRMS results, two groups of organic contaminants viz., phthalate esters and polycyclic aromatic hydrocarbons were detected in most of the sediments of Ennore Creek. Table-1 lists the contaminants found in the sediments from each of the sampling stations and their concentration.

Phthalate esters: Phthalates, or phthalate esters, are esters of phthalic acid and are mainly used as plasticizers. They are chiefly used to turn polyvinyl chloride from a hard plastic into a flexible plastic. Phthalate esters are the dialkyl or alkyl aryl esters of phthalic acid. The phthalates show low water solubility, high oil solubility and low volatility. They are colourless, odourless liquids produced by reacting phthalic anhydride with an appropriate alcohol. Phthalates are important industrial chemicals used in a wide variety of plastic products. Since the first application as plasticizers in the 1930s, phthalates have become one of the most widely spread contaminants in the modern world. Unlike persistent organic pollutants, phthalates and their metabolites do not accumulate in the environment and have a short-half life in living organisms. They are nonetheless a constant presence in all human exposure pathways.

Table-1 shows the presence of phthalic acid, nonyl 2pentyl ester, which is a phthalate ester, in station 3 with the 
concentration of $2.590 \mathrm{mg} / \mathrm{g}$. The organic contaminant, 1,2benzenedicarboxylic acid, diisooctyl ester is present in stations $1,2,4,6,7,8$ and 10 , with the minimum $(0.002 \mathrm{mg} / \mathrm{g})$ and maximum concentration $(5.202 \mathrm{mg} / \mathrm{g})$ in station 7 and 6 respectively. 1, 2-benzenedicarboxylic acid, diisooctyl ester or diisooctyl phthalate (DIOP) is an all-purpose plasticizer for poly(vinyl chloride), poly(vinyl acetate), rubbers, cellulose plastics and polyurethane. In Australia, 1,2-benzene dicarboxylic acid diisooctyl ester is imported and used in rubber compounds for the manufacture of automotive hoses and parts ${ }^{11}$. Point source of the most widely studied and harmful phthalate, diethyl hexyl phthalate (DEHP), are primarily from emissions or spills from sites that use diethyl hexyl phthalate in their manufacturing processes. Rating of diethyl hexyl phthalate is 1.2 on an environmental spectrum of 0-3 to assess the relative hazard to the environment, which indicates that it, may pose a risk to the environment. Diethyl hexyl phthalate concentrations in the water and sediment samples ranged from 0.5 to $23.9 \mu \mathrm{g} / \mathrm{g}$ in the Taiwan river sediments ${ }^{12}$.

Polycyclic aromatic hydrocarbons: Polycyclic aromatic hydrocarbons are a group of chemicals that are formed during the incomplete burning of coal, oil, gas, wood, garbage, or other organic substances, such as tobacco and charbroiled meat. There are more than 100 different polycyclic aromatic hydrocarbons. Polycyclic aromatic hydrocarbons generally occur as complex mixtures. Polycyclic aromatic hydrocarbons usually occur naturally, but they can be manufactured as individual compounds for research purposes. As pure chemicals, polycyclic aromatic hydrocarbons generally exist as colourless, white, or pale yellow-green solids. They can also be found in substances such as crude oil, coal, coal tar pitch, creosote and roofing tar. They are found throughout the environment in the air, water and soil. Occurrence of polycyclic aromatic hydrocarbons in the environment is of great concern due to their carcinogenic properties.

Anthracene belongs to the group of polycyclic aromatic hydrocarbons. Anthracene can vary in appearance from a colourless to pale yellow crystal-like solid. Anthracene is used to make dyes, plastics and pesticides. It has been used to make smoke screens and scintillation counter crystals. One of the most common ways anthracene can enter our body is through breathing contaminated air. Exposure can also occur if our skin comes into contact with contaminated soil or products like heavy oils, coal tar, roofing tar or creosote where polycyclic aromatic hydrocarbons have been found. Anthracene has been detected in fumes from vehicle exhaust, coal, coal tar and at hazardous waste sites. The USEPA has indicated that not enough information exists to classify anthracene as a cancer causing substance.

Naphthalene, 1,6,7-trimethyl- is a three carbon alkyl homolog of naphthalene. In the aquatic environment, naphthalenes are especially hazardous polycyclic aromatic hydrocarbons due to their particular combination of mobility, toxicity and general environmental hazard. Alkyl naphthalenes are usually found in the same petroleum products as naphthalenes, often in higher concentration than the parent compound naphthalene. In general, alkyl naphthalenes pose similar hazards or worse hazards than naphthalene.
Phenanthrene is a polycyclic aromatic hydrocarbon composed of three fused benzene rings. The name phenanthrene is a composite of phenyl and anthracene. It provides the framework for the Steroids. In its pure form, it is found in cigarette smoke and is a known irritant, photosensitizing skin to light.

Biphenyl is a low molecular weight, 2-ring polycyclic aromatic hydrocarbon. Exposure to biphenyl has resulted in central nervous system depression, paralysis, convulsions in experimental animals. The biphenyl group is also a common component or base structure for PCBs and various other toxic organic compounds. It is widely used for organic synthesis; heat transfer agent; fungi stat in packaging of citrus fruit; plant disease control; manufacture of benzidine; dyeing assistant for polyesters, intermediate for polychlorinated biphenyls.

Polycyclic aromatic hydrocarbons is seen in many of the stations of Ennore Creek. About $0.111 \mathrm{mg} / \mathrm{g}$ of phenanthrene and $0.118 \mathrm{mg} / \mathrm{g}$ of $9 \mathrm{H}$-fluorene, 9-methylene is oberved in station 3. Anthracene-2-Methyl is present in stations 6 and 10 at levels of 0.369 and $0.067 \mathrm{mg} / \mathrm{g}$ respectively. The organic contaminant naphthalene, 1,6,7-trimethyl- at a concentration level of $0.077 \mathrm{mg} / \mathrm{g}$ is observed from station 2. Biphenyl compounds like 1,1'-biphenyl,3-methyl $(0.540 \mathrm{mg} / \mathrm{g})$ and 1,1'biphenyl,3,4'-dimethyl $(0.056 \mathrm{mg} / \mathrm{g})$ are detected in stations 4 and 2 respectively. Sum of 16 polycyclic aromatic hydrocarbons concentrations were in the range of 8.80-18 ng/g dry weight in the sediments from the marine environment of Korea. Industrialized and urbanized region showed high level of polycyclic aromatic hydrocarbons contamination ${ }^{13}$. Petroleum refineries have been reported to be a source of polycyclic aromatic hydrocarbons in different places. Combustion products from a refinery in the Gulf of Oman contained substantial concentrations of carcinogenic polycyclic aromatic hydrocarbon that contaminated the sediments ${ }^{14}$. The sources of polycyclic aromatic hydrocarbons in Xiamen Bay were mainly urban discharge, industry and combustion of fuels ${ }^{15}$. On an environmental spectrum of 0-3 polycyclic aromatic hydrocarbons registers 1.5 , which may pose a risk to the environment ${ }^{11}$.

Other organic pollutants: The other chemicals that are reported are methoxyacetic acid, 2-tetradecyl ester, benzenecycloheptatriene, butanoic acid, 3-[(1-phenyl-2-propynyl) oxy]. The GC/Ms result of station 9 is blank indicating the absence of high molecular weight organic pollutants. Benzocycloheptatriene $(1.507 \mathrm{mg} / \mathrm{g})$ and butanoic acid, 3-[(1phenyl-2-propynyl) oxy] (1.452 $\mathrm{mg} / \mathrm{g})$ are seen in station 5 . About $1.323 \mathrm{mg} / \mathrm{g}$ of methoxyacetic acid, 2-tetradecyl ester in station 6 were identified.

Sediment characteristics: The sediment composition of the samples from all the stations indicates that the Creek is dominated by sandy-silt or silty-sand sediments (Table-2). The minimum and maximum clay content is reported in station 2 $(0.03 \%)$ and in station $5(0.11 \%)$ respectively. Sampling station 10 , the mouth of the creek which is completely sandy as it joins the sea. Highest percentage of silt and lowest percentage of sand is observed in station 4 . The results are comparable with Thangadurai et al. ${ }^{16}$ and Seshan et al. ${ }^{17}$, who reported that the sediments of the Ennore Creek were mostly sandy silt and silty sand. 
Total organic carbon of sediment within the sampling stations varies from 0 to $13.7 \%$ (Table-2). The stations 5 and 6 show higher total organic carbon content of $13.7 \%$ and $9 \%$ respectively. Station 8 did not show the presence of total organic carbon. The reasons for which could not be traced out. Lowest levels of total organic carbon are seen in stations 2 and 10.

Correlation of sediment characteristics with levels of organic pollutants: The rank correlation of sediment composition and the total organic carbon with the levels of total organic pollutants in each sampling station of Ennore creek was calculated (Table-3). The total organic pollutants is the sum total of the concentration of all the organic pollutant present in each station. From the table it is observed that there exists a positive correlation between the total organic pollutants and the clay content as well as with the silt content. But a negative rank correlation is seen between sand content and the total organic pollutants which coincides with the earlier observations. Highest positive correlation exists between total organic carbon and the clay content as well as total organic pollutant and total organic carbon. There exists a positive correlation among the total organic carbon and the concentration of the 1,2-benzenedicarboxylic acid, diisooctyl ester, which is found in most of the stations. The organic compound DIOP is found in majority of the stations where the total organic carbon exceeds $2 \%$. Among these stations, the concentration of DIOP is found to be the highest $5.202 \mathrm{mg} / \mathrm{g}$ in station 6 which also shows the highest total organic carbon among the stations reporting the presence of DIOP.

\begin{tabular}{ccccc}
\multicolumn{5}{c}{ TABLE-2 } \\
\hline \multicolumn{5}{c}{ SEDIMENT CHARACTERISTICS } \\
\hline Station & Sand $(\%)$ & Silt $(\%)$ & Clay $(\%)$ & TOC $(\%)$ \\
\hline 1 & 58.63 & 41.29 & 0.08 & 5.1 \\
2 & 99.00 & 0.97 & 0.03 & 0.7 \\
3 & 22.77 & 77.18 & 0.05 & 3.7 \\
4 & 17.58 & 82.34 & 0.09 & 5.0 \\
5 & 51.29 & 48.60 & 0.11 & 13.7 \\
6 & 70.70 & 29.20 & 0.10 & 9.0 \\
7 & 86.47 & 13.47 & 0.07 & 2.4 \\
8 & 97.43 & 2.51 & 0.07 & 0.0 \\
9 & 98.61 & 1.33 & 0.06 & 1.2 \\
10 & 99.59 & 0.37 & 0.04 & 0.96 \\
\hline TOC = Total organic carbon & & &
\end{tabular}

\begin{tabular}{cccccc}
\multicolumn{6}{c}{ TABLE-3 } \\
\multicolumn{5}{c}{ CORRELATION OF SEDIMENT PARAMETERS } \\
WITH LEVEL OF ORGANIC POLLUTANTS \\
\hline \multicolumn{7}{c}{ Clay } & Sand & Silt & TOC & TOP \\
\hline Clay & 1 & & & & \\
Sand & -0.6 & 1 & & & \\
Silt & 0.6 & -1 & 1 & & \\
TOC & 0.8 & -0.6 & 0.7 & 1 & \\
TOP & 0.5 & -0.5 & 0.5 & 0.8 & 1 \\
\hline
\end{tabular}

TOC $=$ Total organic carbon; $\mathrm{TOP}=$ Total organic phosphorus.

\section{Conclusion}

The sediment samples are highly contaminated by various organic pollutants such as:

Phthalate esters-1,2-benzenedicarboxylic acid, diisooctyl ester, Phthalic acid, nonyl 2-pentyl ester; polycyclic aromatic hydrocarbons-naphthalene, 1,6,7-trimethyl-, phenanthrene, 9H-fluorene, 9-methylene, anthracene,2-methyl-, 1,1'-biphenyl, 3-methyl, 1,1'-biphenyl,3,4'-dimethyl- and other organic contaminants- benzocycloheptatriene, butanoic acid, 3-[(1phenylethyl-2-propynyl)oxy], methoxyacetic acid, 2-tetradecyl ester.

The most abundant organic pollutant is the phthalate esters of high molecular weight followed by polycyclic aromatic hydrocarbons which could be originated from refineries and other chemical industries. The results of sediment composition show that the Ennore Creek Sediment is sandysilt to silty-sand.

\section{REFERENCES}

1. M.R. Hurst, J. Balaam, Y.L. Chan-Man, J.E. Thain and K.V. Thomas, Marine Pollut. Bull., 49, 648 (2004).

2. R. Clapp and R. Ozonoff, Lancet, 355, 1006 (2000).

3. D.R. Anderson and R. Fisher, Chemosphere, 46, 371 (2002).

4. P.H. Dyke, C. Foan and H. Friedler, Chemosphere, 50, 469 (2003).

5. B. Men, M. He, L. Tan, C. Lin and X. Quan, Marine Pollut. Bull., 58, 818 (2009)

6. ICMAM, Report, Waste Load Allocation and Waste Assimilation Capacity for Ennore and North Chennai Coastal Waters, pp. 5-21 (2004).

7. USEPA Method 8280A. Polychlorinated Dibenzodioxins (PCDDs) and Polychlorinated Dibenzofurans (PCDFs) by High Resolution Gas Chromatography/Low Resolution Mass Spectrometry (HRGC/LRMS), (1998).

8. B.A. Schumacher, Methods for the Determination of Total Organic Carbon (TOC) in Soils and Sediments, (NCEA-C-1282, EMASC-001), (2002).

9. W.C. Krumbein and F.J. Pettijohn, Manual of Sedimentary Petrography, D. Appleton Century Co. Inc., New York (1938).

10. S.C. Gupta and V.K. Kapoor, Fundamentals of Applied Statistics. (Reprint), Sultan Chand and Sons, edn. 4 (2008).

11. National Pollution Inventory of Australia, Emission Estimation Technique Manual for Inorganic Chemicals Manufacturing (2004).

12. S.Y. Yuan, C. Liu, C.S. Liao and B.V. Chang, Chemosphere, 49, 1295 (2002).

13. U.H. Yim, S.H. Hong and W.J. Shim, Chemosphere, 68, 85 (2007).

14. I. Tolosa, S.J. de Mora, S.W. Fowler, J.-P. Villeneuve, J. Bartocci and C. Cattini, Marine Pollut. Bull., 50, 1619 (2005).

15. X.H. Wang, L. Xu and W.Q. Chen, Chinese J. Oceanol. Limnol., 17, 247 (1999)

16. N. Thangadurai, S. Srinivasalu, M.P. Jonathan, N.R. Rao and R.S. Kumar, Indian J. Marine Sci., 34, 274 (2005).

17. B.R.R. Seshan, U. Natesan and K. Deepthi, Environ. Earth Sci., 66, 489 (2011). 